\title{
The role of measurement accuracy on the heat stress assessment according to ISO 7933: 2004
}

\author{
F. R. d'Ambrosio Alfano ${ }^{1}$, B. I. Palella ${ }^{2}$ \& G. Riccio ${ }^{2}$ \\ ${ }^{1}$ DIMEC, Dipartimento di Ingegneria Meccanica, \\ Università di Salerno, Italy \\ ${ }^{2}$ DETEC, Dipartimento di Energetica, Termofluidodinamica Applicata e \\ Condizionamenti Ambientali, Università di Napoli Federico II, Italy
}

\begin{abstract}
The thermo-hygrometric risk analysis, regulated by several International Standards, is one of the more relevant facets of workplace assessment. Based on the predicted heat strain (PHS) model, the last version of ISO Standard 7933 devoted to the hot stress evaluation requires the measure of four physical (air temperature, mean radiant temperature, humidity and air velocity) and two subjective (metabolic rate and thermal clothing insulation) parameters. As far as the measurement of microclimatic parameters is concerned, ISO 7726 Standard suggests minimum and maximum accuracy values. On the other hand, for subjective measurements the situation does not appear so clear since the metabolic rate accuracy requirements are strictly related to the calculation method, whereas any accuracy is actually suggested for the clothing insulation evaluation. In order to evaluate the effect of the measurement accuracy on the reliability of the hot stress assessment, this work reports a sensitivity analysis of the PHS model to its independent variables. The results obtained clearly show that the mean radiant temperature measurement appears a tricky matter since only an error within the accuracy range can result in a very strong overestimation (up to 5 hours) of allowable exposure times.

Keywords: heat stress assessment, accuracy, predicted heat strain.
\end{abstract}

\section{Introduction}

In the last sixty years several efforts have been devoted by the scientific community to the formulation of a reliable index/method for the heat stress 
assessment [1, 2]. The different ways of treating the matter result in an impressing number of indices (often empirical) characterised by a balanced compromise among the reliability of the assessment, a user-friendly calculation and a reduced number of measurements. In spite of this apparent confusion, the ISO layout for hot extreme environments [3] is very clear: for a rough preliminary assessment the calculation of the WBGT index [4], whereas, for an in-depth analysis of the working situation, the Predicted Heat Strain (PHS) approach [5], are required. Based on the heat balance equation of the human body $[6,7]$, PHS method requires the measure of four physical (air temperature, mean radiant temperature, humidity and air velocity) and two subjective (metabolic rate and thermal clothing insulation) variables in order to evaluate maximum allowable exposure time compatible with a limit rectal temperature of $38^{\circ} \mathrm{C}$ and a maximum water loss of $5 \%$ of the overall subject weight [5].

Since the thermal response of the subject predicted by PHS model is strictly related to the six variables quoted above, both accuracy and a right procedure for measuring the whole of the variables involved in the assessment appear a crucial need: as a matter of fact one or more errors could result in a wrong estimation of the maximum allowable exposure time.

On this point of view we need to underline that:

- ISO 7726 Standard [8] suggests the minimum characteristics (required and desirable) of instruments for measuring the four physical parameters;

- ISO 8996 Standard [9] specifies methods for estimating metabolic rate and their accuracy on the base of four different measurement levels (screening, observation, analysis and expertise), suggesting as far as possible, the most thorough method.

- ISO/DIS 9920 Standard [10] deals with methods for estimating thermal characteristics of clothing ensemble, also taking into account the pumping effect due to body movements [11] but it does not suggest their accuracy.

The need of a right heat stress assessment provided some crucial answers:

- Minimum and maximum accuracy levels required by Standards actually in force are enough for a reliable assessment of the working situation?

- In case suggested accuracy levels should not be enough, what kind of strategy is required?

- Which variables play a more significant role in the assessment phase? Microclimatic ones? Subjective ones or both?

In order to thoroughly answer these questions a valid investigation tool is undoubtedly the sensitivity analysis of PHS model to its independent variables. On one hand this approach allows to establish how the measurement errors affect the heat stress assessments; on the other one it could suggest more or less restrictive accuracy requirements with the consequent choice of more adequate measurements devices or methods.

\section{Methods}

As the mathematical function binding subjective and microclimatic variables to the physiological response of the subject to the thermal environment according to 
the PHS model is not handy to treat $[5,11]$, the sensitivity analysis has been carried out by means of a special software designed according to ISO 7933 [11]. More in particular, this software is able to return:

a) The final values of the rectal temperature and the water loss after eight hours of continuous work starting from a full data set of two subjective and four microclimatic parameters;

b) Temperature-humidity limit curves allowing 8 hours of continuous work starting from a data set of two subjective and two microclimatic (mean radiant temperature and air velocity).

Two levels of subjective variables have been investigated: concerning the metabolic rate $(\mathrm{M})$ 1,7 and 2,8 met corresponding to a light and a moderate activity [9], whereas, concerning the clothing insulation $\left(\mathrm{I}_{\mathrm{cl}}\right)$ 0,60 and 1,0 clo, typical values of summer and winter clothes [10]. As far as the microclimatic parameters are concerned, table 1 summarizes the investigated ranges of air temperature, mean radiant temperature, air velocity and humidity.

Table 1: $\quad$ Microclimatic variables ranges investigated.

\begin{tabular}{|l|l|l|}
\hline \multicolumn{1}{|c|}{ Microclimatic variable } & \multicolumn{1}{c|}{ Symbol } & \multicolumn{1}{c|}{ Range } \\
\hline Air velocity & $\mathrm{V}_{\mathrm{a}}$ & $0,20 \mathrm{~m} / \mathrm{s}$ \\
\hline Mean radiant temperature & $\mathrm{t}_{\mathrm{r}}$ & $15 \div 45^{\circ} \mathrm{C}$ \\
\hline Air temperature & $\mathrm{t}_{\mathrm{a}}$ & $15 \div 45^{\circ} \mathrm{C}$ \\
\hline Humidity ratio & $\mathrm{RH}$ & $0 \div 100 \%$ \\
\hline
\end{tabular}

Table 2 briefly summarises the whole of the non-measurable parameters (i.e. weight, height, posture, acclimatization status, drinking possibility and so on), required by PHS for the hot stress assessment [5].

Table 2: $\quad$ Non-measurable parameter values required by PHS method [5].

\begin{tabular}{|l|l|}
\hline \multicolumn{1}{|c|}{ Parameter } & \multicolumn{1}{c|}{ Value } \\
\hline Weight & $75 \mathrm{~kg}$ \\
\hline Height & $1,70 \mathrm{~m}$ \\
\hline Posture & Standing \\
\hline Clothing vapour permeability & 0,38 \\
\hline Acclimatization status & Not acclimatised \\
\hline Freely drinking possibility & Yes \\
\hline
\end{tabular}

The sensitivity analysis reported here, by varying each variable in the range of desired and required accuracy required by ISO 7726 Standard [8] for typical hot stress situation (S class), has been carried out. Concerning clothing insulation an accuracy of $\pm 10 \%$ has been used, since any indication is actually required by ISO/DIS 9920 [10]. About the metabolic rate accuracy ISO 8996 reports typical precision values in the range $5 \div 20 \%$ depending on the method used for the evaluation of the metabolic rate (i.e. tables, heart rate measurement, oxygen consumption measurement, double labelled water method, direct calorimetry) [9]. We made use of a value $\pm 10 \%$ corresponding to the typical 
accuracy of metabolic rate assessed by means of the heart frequency values. A summary of investigation is reported in table 3 .

Table 3: $\quad$ Summary of accuracy values used in this investigation.

\begin{tabular}{|c|c|c|}
\hline Variable & Required Accuracy & Desired Accuracy \\
\hline $\mathrm{t}_{\mathrm{a}}$ & $\pm 0,50^{\circ} \mathrm{C}$ & $\pm 0,25^{\circ} \mathrm{C}$ \\
\hline $\mathrm{t}_{\mathrm{r}}$ & \multicolumn{2}{|c|}{ $\pm 5,00^{\circ} \mathrm{C}$} \\
\hline $\mathrm{V}_{\mathrm{a}}$ & $\pm\left(0,1+0,05 \mathrm{v}_{\mathrm{a}}\right)$ & $\pm\left(0,05+0,05 \mathrm{v}_{\mathrm{a}}\right)$ \\
\hline $\mathrm{p}_{\mathrm{a}}$ & \multicolumn{2}{|c|}{ $\pm 0,15 \mathrm{kPa}$} \\
\hline $\mathrm{M}$ & \multicolumn{2}{|c|}{ $\pm 10 \%$} \\
\hline $\mathrm{I}_{\mathrm{cl}}$ & \multicolumn{2}{|c|}{} \\
\hline
\end{tabular}

The calculation phase has been organized in three different steps:

1) Starting from nominal values of each variable, temperature-humidity curves (called nominal limit curves) corresponding to 8 hours of continuous work have been preliminarily obtained. By this way safe working conditions have been depicted on special psychometrics charts (fig. 1 and fig. 2).

2) In the second phase each variable (subjective or physical) has been "disturbed" of an amount equal to its accuracy (required and desired according to tab. 3 ) in order to highlight the nominal limit curve shifting and the onset of uncertain regions.

3) On the over nominal limit curve the maximum allowable exposure times have been finally calculated taking into account the measurement errors: by this way the accuracy effect in terms of the corresponding reduction of the allowable exposure times has been expressed (fig. 3).

\section{Results and discussion}

Figure 1 shows the effect on accuracy of subjective parameters on the nominal limit curves under typical summer/winter clothing situations and for two metabolic rate levels. Fig 1A clearly highlights an even reduced error on the metabolic rate assessment, which strongly affects the safety regions amplitude. As a matter of fact, for 1,7 met (continuous curves in fig. 1), the variation of the metabolic rate within its accuracy $( \pm 10 \%)$ results in a shift of the nominal limit curve corresponding to an uncertainty region of about $2,6 \div 2,9^{\circ} \mathrm{C}$ at 0,6 clo $(3,1 \div 3,6$ at 1,0 clo) depending on the humidity levels. It is noteworthy to point out that, according to our early findings [12], the discontinuity of limit curves (more evident at lower metabolic rate) is mainly due to the different protection criterion required for the assessment phase. More in particular at lower temperature and high humidity values the sweating efficiency is so low that the subject is not able to get over the heat accumulation reaching a core temperature of $38^{\circ} \mathrm{C}$, whereas, at lower humidity levels and higher temperatures, the sweating mechanism is so efficient that after $8 \mathrm{~h}$ of continuous work maximum water loss is reached. An amplified behaviour for $\mathrm{I}_{\mathrm{cl}}=1,0$ clo has been obtained with a general increasing trend of uncertainty regions especially at a higher metabolic 
rate (dashed curves). According to fig. 1B, the clothing insulation accuracy effect appears undoubtedly milder $\left(3,0^{\circ} \mathrm{C}\right.$ of uncertainty at 2,8 met and 1,0 clo) while a simultaneous error on both subjective variables (fig. 1C) results in an almost randomness of the thermal environment assessment since the width of uncertainty regions reaches $7,0^{\circ} \mathrm{C}$.

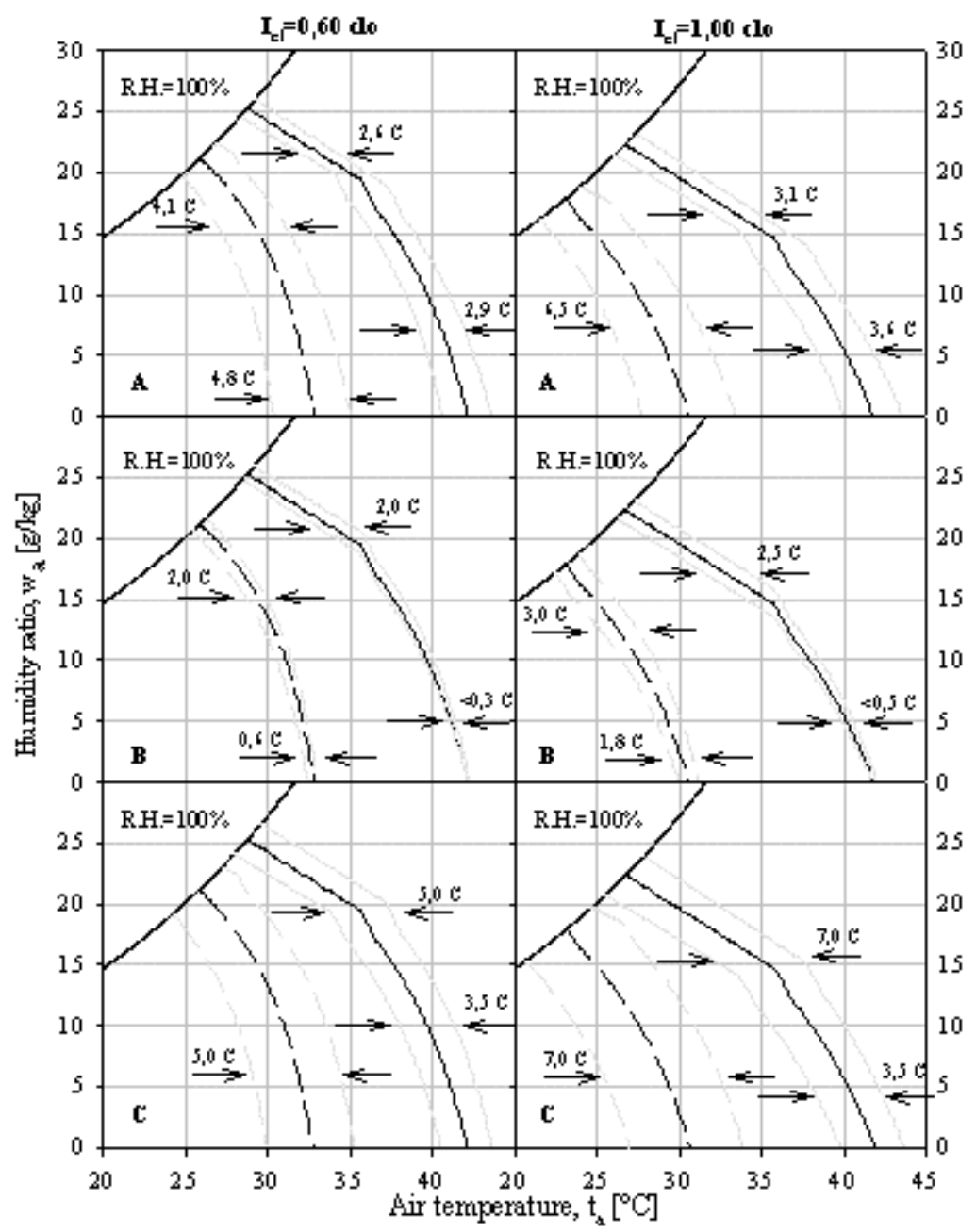

Figure 1: Effect of a $\pm 10 \%$ measurement error (grey lines) on the metabolic rate (A), the clothing insulation (B) and both metabolic rate and clothing insulation (C) on the nominal exposition limit curves (black lines) corresponding to 8 hours of continuous work. Metabolic rate: 1,7 met (continuous curves), 2,8 met (dashed curves); absolute air velocity, $\mathrm{v}_{\mathrm{a}}=0,20 \mathrm{~m} / \mathrm{s},\left(\mathrm{t}_{\mathrm{a}}=\mathrm{t}_{\mathrm{r}}\right)$. 


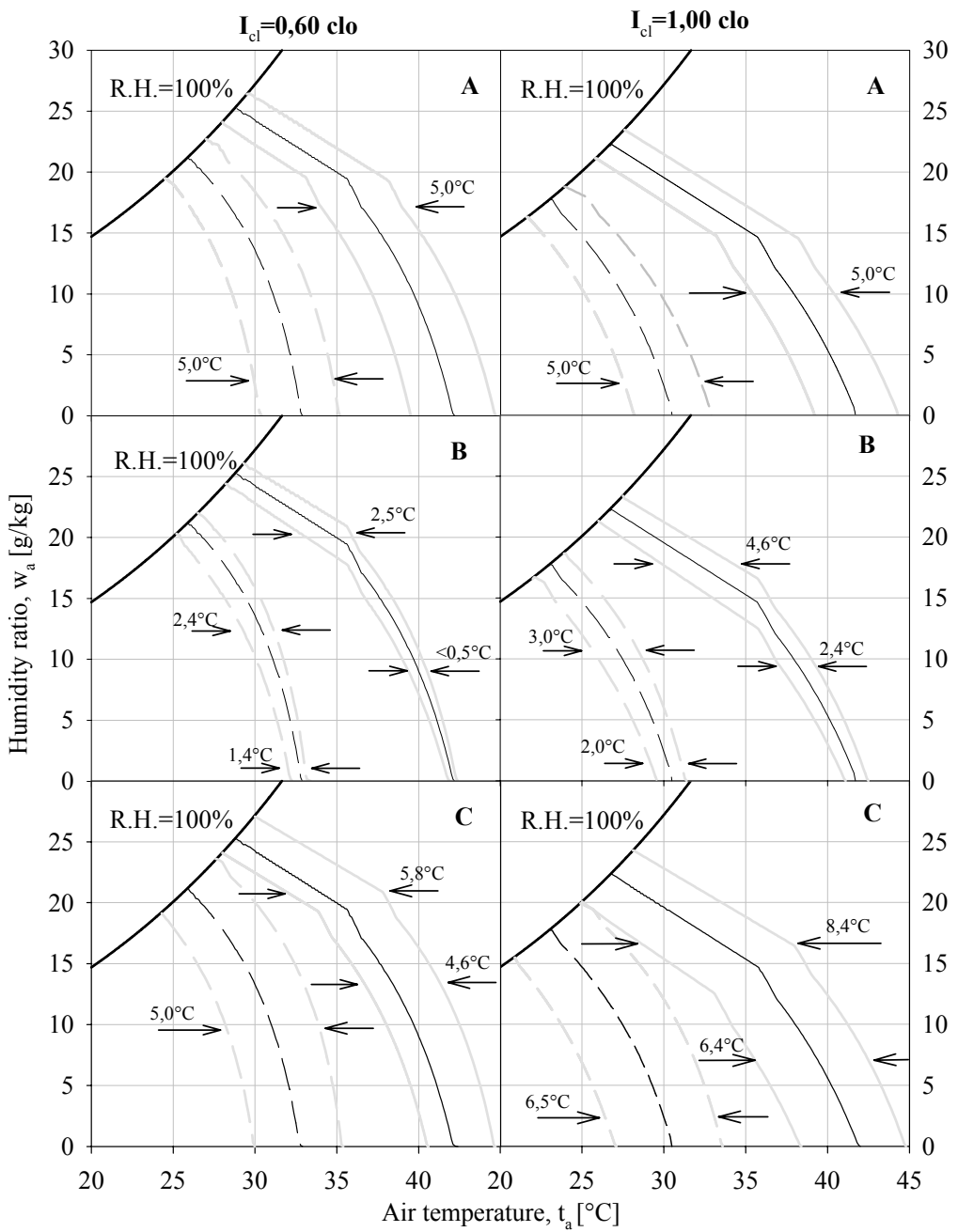

Figure 2: Effect of the measurement accuracy of the mean radiant temperature (A), the air velocity (B) and the whole of physical parameters (C) on the nominal limit curves (black lines) corresponding to 8 hours of continuous work according to ISO 7933. Metabolic rate: 1,7 met (continuous curves), 2,8 met (dashed curves); absolute air velocity, $\mathrm{v}_{\mathrm{a}}=0,20 \mathrm{~m} / \mathrm{s},\left(\mathrm{t}_{\mathrm{a}}=\mathrm{t}_{\mathrm{r}}\right)$. Grey curves refer to the required accuracy values suggested by ISO 7726 Standard.

A similar investigation has been carried out on the effect of required accuracy of physical parameters, as shown in fig. 2 .

Fig. 2A clearly shows up a strong effect of the mean radiant temperature on the thermal stress assessment [13]: in fact, a $t_{r}$ error within the required accuracy 
results in an uncertainty area width of about $5,0^{\circ} \mathrm{C}$ (for both $\mathrm{M}$ and $\mathrm{I}_{\mathrm{cl}}$ investigated values). On the contrary hand, the air velocity (fig. $2 \mathrm{C}$ ) exhibits a slighter sensitivity with smaller areas (in the $0,3 \div 3,0^{\circ} \mathrm{C}$ depending on the metabolic rate and the clothing insulation).

According to fig. $2 \mathrm{C}$, where the whole of the microclimatic variables have been taken into account, a reliable assessment of working conditions appears almost a hard matter since the presence of measurement errors result in uncertain areas wider than $8,0^{\circ} \mathrm{C}$ with unexpected effects on the health care of workers. A similar investigation on the desired accuracy levels has been carried out (only for $\mathrm{t}_{\mathrm{a}}$ and $\mathrm{v}_{\mathrm{a}}$ according to tab. 3), showing only a milder effect.

In order to lead to the formulation of a relative scale of sensitivity to errors on the hot stress assessment carried out according to PHS method, in figure 3 the variations of allowable exposure times $\left(\Delta D_{\text {lim }}\right)$ obtained by "disturbing" over nominal limit curves each parameter of an amount equal to its required or desired accuracy, has been reported. This kind of analysis should be generally described by means of a special 3-d plot (temperature-humidity-exposure time). In order to avoid a complex representation, two combined plots have been used: in the lower box for the desired metabolic rate activity the nominal microclimatic conditions (evaluated in the absence of errors) allowing 8 hours of continuous work have been depicted; following the arrow, the corresponding reduction of the exposure time (with respect to $8 \mathrm{~h}$ ) calculated taking into account errors on each parameter on the upper plots has to be read.

Obtained results lead to highlight several interesting features:

1) For moderate metabolic activities ( $M=1,7 \mathrm{met})$ a dual behaviour depending on the working place humidity has been found:

- under hot and dry condition (i.e. $\mathrm{RH}<50 \%$ ) the variation of allowable exposure times does not appear very significant (only metabolic rate and the mean radiant temperature, according to previous results on the thermal comfort assessment [13], exhibit a reduction of the allowable exposure times of almost $60 \mathrm{~min}$ and $90 \mathrm{~min}$, respectively) with the following relative sensitivity scale:

$$
\mathrm{t}_{\mathrm{a}, \mathrm{des}} \cong \mathrm{t}_{\mathrm{a} \text {,req }}<\mathrm{I}_{\mathrm{cl}} \cong \mathrm{v}_{\mathrm{a}, \mathrm{des}} \cong \mathrm{p}_{\mathrm{a}}<\mathrm{v}_{\mathrm{a}, \text { req }}<\mathrm{M}<\mathrm{t}_{\mathrm{r}}
$$

- under hot and humid conditions (i.e. $\mathrm{RH}>50 \%$ ) a dramatic decreasing of allowable exposure times has been observed (more than $5 \mathrm{~h}$ ) with the following sensitivity scale:

$$
\mathrm{t}_{\mathrm{a} \text {,des }}<\mathrm{t}_{\mathrm{a} \text {,req }}<\mathrm{I}_{\mathrm{cl}}<\mathrm{v}_{\mathrm{a} \text {,des }}<\mathrm{M} \cong \mathrm{p}_{\mathrm{a}}<\mathrm{v}_{\mathrm{a} \text {,req }}<\mathrm{t}_{\mathrm{r}}
$$

2) For higher metabolic rates $(M=2,8 \mathrm{met})$ above quoted phenomena begin to disappear with a more homogeneous behaviour. As a matter of fact the sensitivities to the air temperature, the air velocity (within the desirable accuracy range), humidity and the clothing insulation appear almost negligible (the allowable exposure time reduction has always been in the range $20 \div 60$ min) on the whole limit curve, while only for highest humidity values $(\mathrm{RH}>70 \%)$ an "on-off" behaviour similar to that observed at lower metabolic rate has been detected. 


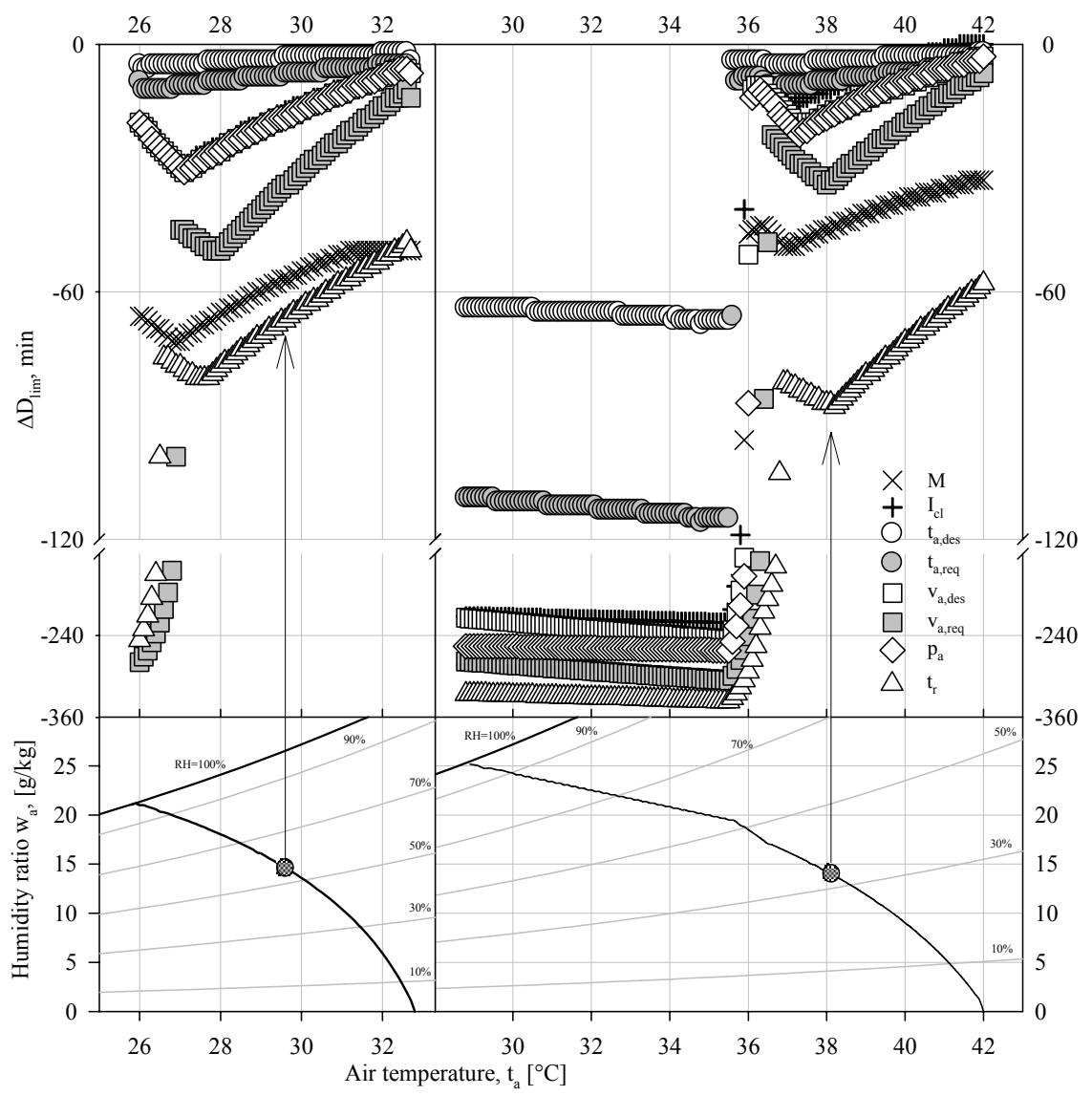

Figure 3: $\quad$ Sensitivity of the PHS model to the measurement errors. Nominal values of independent variables: $M=1,70$ met (right side), $M=2,80$ met (left sides), $\mathrm{I}_{\mathrm{cl}}=0,60$ clo, $\mathrm{v}_{\mathrm{a}}=0,20 \mathrm{~m} / \mathrm{s}$. On the upper side the reduction of exposition times $\Delta \mathrm{D}_{\text {lim }}$ with respect to microclimatic states corresponding to $8 \mathrm{~h}$ of continuous work (reported on the lower side) have been reported.

In these cases errors due to the mean radiant temperature and the air velocity (within the required accuracy range) lead to an overestimation of allowable exposure times more than $4 \mathrm{~h}$. Finally, the sensitivity scale obtained in such conditions was:

$$
\mathrm{t}_{\mathrm{a}, \mathrm{des}} \cong \mathrm{I}_{\mathrm{cl}} \cong \mathrm{v}_{\mathrm{a} \text {,des }} \cong \mathrm{t}_{\mathrm{a} \text {,req }} \cong \mathrm{p}_{\mathrm{a}}<\mathrm{M}<\mathrm{v}_{\mathrm{a}, \text { req }}<\mathrm{t}_{\mathrm{r}}
$$

Observed phenomena could be explained taking into account the different efficiency of thermoregulations mechanisms, by changing microclimatic conditions, on which the PHS model is based [7]. According to this hypothesis, under hot dry microclimatic conditions (where the maximum exposure time is related to the attainment of the maximum water loss), lower humidity values 
result in a highest efficiency of sweating, therefore a little perturbation of any parameter is easily counterbalanced by the human body. On the contrary hand, under hot humid situations (where the maximum exposure time is related to the attainment of the maximum rectal temperature), the lowest sweating efficiency combined with a lowest evaporative driving force avoids an effective removal of the heat accumulation so much that even a little variation of the parameters results in a dramatic reduction of exposure times. In other words, the PHS models appear more sensitive to the whole of the microclimatic situations where the behavioural thermoregulation mechanism efficiency is poor.

\section{Conclusions}

This paper has been devoted to the measurement error effect of subjective and microclimatic parameters involved in the hot stress assessment carried out according to ISO 7933 Standard. The data elaborations by means of special software designed in accordance with thermal environment Standards actually under force has been carried out.

Obtained results highlight a behaviour strictly related to the efficiency of thermoregulation mechanisms regulating the heat accumulation removal. In particular, at lower metabolic rate, in the whole of situations characterised by a reduced efficiency of sweating mechanism, the obtained sensitivity scale has clearly shown the crucial role of mean radiant temperature measurement whose errors can lead to an underestimation of maximum allowable exposure time of more than 5 hours. A strong effect of the air velocity errors and a milder influence of metabolic rate and clothing insulation have been also detected.

Under higher metabolic rates (high sweat production) or drier microclimatic situations (high sweating efficiency) the effects of measurement errors seems to be milder, although the sensitivity to the mean radiant temperature still appears a crucial matter.

Finally, the strong uncertainty of the hot stress assessment related to the mean radiant temperature measurement would make either an increase of accuracy required by ISO 7726 for Class S devices or turning to more careful measurement techniques (i.e. indirect methods as the plane radiant temperature methods) necessary. Similar interventions to the air velocity and the humidity accuracies, which often affect the "subject-environment" heat transfer should be hoped. Concerning subjective parameters more thorough method should be devoted only for higher metabolic rates or clothing insulation values.

\section{Acknowledgements}

This work was funded by the Italian MURST (Italian Ministry for University and Scientific-Technological Research) in the area of the PRIN COFIN 2005 Project entitled "Studio termofluidodinamico di componenti di facciata adattativi per il comfort ed il risparmio energetico". 


\section{References}

[1] Lee, D.H.K., Seventy-five years of searching for a heat index. Environmental Research 22, pp. 331-356, 1980.

[2] d'Ambrosio Alfano, F.R. Palella, B.I., Riccio, G., Manuscript under preparation.

[3] ISO, 2004. Ergonomics of the thermal environment - Risk assessment strategy for the prevention of stress or discomfort in thermal working conditions - ISO Standard 15265 - Geneva: International Standardization Organization.

[4] ISO, 1989. Hot environments - Estimation of the heat stress on working man, based on WBGT-index (wet bulb globe temperature) - ISO Standard 7243. Geneva: International Standardization Organization.

[5] ISO, 2004. Ergonomics of the thermal environment - Analytical determination and interpretation of heat stress using calculation of the predicted heat strain. ISO Standard 7933. Geneva: International Standardization Organization.

[6] Fanger, P.O., Thermal Comfort. McGraw-Hill, New York, 1970.

[7] Malchaire, J.B., Piette, A., Kampmann, B., Menhert, P., Gebhardt, H., Havenith, G., Den Hartog, E., Holmer, I., Parsons, K., Alfano, G., Griefahn, B., Development and Validation of the Predicted Heat Strain Model. Annals of Occupational Hygiene, 45(2), pp. 123-135, 2001.

[8] ISO, 1985. Thermal environments - Instruments and methods for measuring physical quantities. Geneva: International Standardization Organization.

[9] ISO, 2004. Ergonomics of the thermal environment - Determination of metabolic rate - ISO Standard 8996. Geneva: International Standardization Organization.

[10] ISO, 2004. Ergonomics of the thermal environment - Estimation of the thermal insulation and evaporative resistance of a clothing ensemble ISO/DIS 9920. Geneva: International Standardization Organization.

[11] d'Ambrosio Alfano, F.R., Palella, B.I., Riccio, G., TEE (Thermal Environment Assessment): a friendly tool for thermal environment evaluation. Proc. Of. 11th International Conferences on Environmental Ergonomics, Eds. Ingvar Holmér, Kalev Kuklane and Chuansi Gao, pp.503-506, 2005.

[12] d'Ambrosio Alfano, F.R., Palella, B.I., Riccio, G., Criteria for assessment of hot environments: WBGT index and PHS (predicted heat strain). Medicina del Lavoro, 95(4), pp. 255-280, 2004.

[13] d'Ambrosio Alfano, F.R., Dell'Isola, M., Palella, B.I., Riccio, G., Russi, A., La misura della Temperatura Radiante. Atti del $61^{\circ}$ Congresso Nazionale ATI, Eds. Morlacchi Editore: Perugia (Italy), pp. 285-290, 2006 (in Italian). 